\title{
Article \\ Development of an Agar Bioassay Sensitivity Test in Alopecurus myosuroides for the Pre-Emergence Herbicides Cinmethylin and Flufenacet
}

\author{
Miriam H. Messelhäuser ${ }^{1}{ }^{*}$, Alexander I. Linn ${ }^{1}$, Anna Mathes ${ }^{1}$, Bernd Sievernich ${ }^{2}$ and Roland Gerhards ${ }^{1}$ \\ 1 Department of Weed Science, University of Hohenheim, 70593 Stuttgart, Germany; \\ alinn@uni-hohenheim.de (A.I.L.); Anna.gruenberger@web.de (A.M.); \\ roland.gerhards@uni-hohenheim.de (R.G.) \\ 2 ASF SE, Speyerer Straße 2, 67117 Limburgerhof, Germany; bernd.sievernich@basf.de \\ * Correspondence: Miriam.messelhaeuser@uni-hohenheim.de
}

Citation: Messelhäuser, M.H.; Linn, A.I.; Mathes, A.; Sievernich, B.; Gerhards, R. Development of an Agar Bioassay Sensitivity Test in Alopecurus myosuroides for the Pre-Emergence Herbicides Cinmethylin and

Flufenacet. Agronomy 2021, 11, 1408 https://doi.org/10.3390/ agronomy 11071408

Academic Editors: Antonia

María Rojano-Delgado and Ricardo Alcántara-de la Cruz

Received: 21 May 2021

Accepted: 12 July 2021

Published: 14 July 2021

Publisher's Note: MDPI stays neutral with regard to jurisdictional claims in published maps and institutional affiliations.

Copyright: (c) 2021 by the authors. Licensee MDPI, Basel, Switzerland. This article is an open access article distributed under the terms and conditions of the Creative Commons Attribution (CC BY) license (https:// creativecommons.org/licenses/by/ $4.0 /)$.

\begin{abstract}
Rapid and reliable tests for pre-emergence herbicide susceptibility in weeds are important to test a wider range of accessions on their baseline sensitivity, as well as to provide information on putative resistance. This study focused on the development of an agar quick test to determine sensitivity differences in Alopecurus myosuroides Huds. to pre-emergence herbicides containing flufenacet and cinmethylin. The new agar quick test and a standardized whole plant pot bioassay were conducted twice in 2019. For both test systems, seeds of 18 populations of $A$. myosuroides originated from Southwest Germany and Great Britain were used and treated with discriminating rates of herbicides in dose-response studies. After 28 days, the above-ground dry matter of the plants was determined and the resistance factors were calculated. The agar test was able to provide information on the resistance status of the tested biotype within 12 days. All populations did not show reduced sensitivity to cinmethylin. Within three populations, differences in sensitivity levels were observed between the two test systems. As cinmethylin is not yet marketed in Europe, these resistance factors can also be considered as a baseline sensitivity for A. myosuroides. For flufenacet, the resistance factors differed significantly from the whole plant pot bioassay and the agar test for the biotypes $\mathrm{A}(0.35,13.1), \mathrm{C}(0.56,13.2), \mathrm{D}(1.87,12.4), \mathrm{E}(15.5,3.5)$ and $\mathrm{H}(2.95,14)$. It was possible for the most part for the cinmethylin tested populations to confirm the results of the standardized whole plant pot bioassay in the agar bioassay sensitivity tests, and hence create a promising, faster test system.
\end{abstract}

Keywords: whole plant biotest; quick test; black-grass; herbicide resistance detection; VLCFA; new mode of action

\section{Introduction}

Herbicides are most effective in controlling weeds in modern agricultural systems and hence in safeguarding and maintaining crop yield and quality. Due to the shortage of new modes of action since the 1990s, the range of herbicides for weed control is even more limited [1-4]

The repeated use of herbicides with the same mode of action create resistant individuals within the population and significantly reduces weed control efficacy [5,6]. Currently, there are 262 known herbicide-resistant weeds that are resistant to 23 of the 26 existing modes of action [7]. Several weed species including Alopecurus myosuroides Huds. (Blackgrass) express multiple resistance to herbicides with different modes of action [1,2]. Many A. myosuroides populations in Europe are resistant to post-emergent herbicides, inhibiting acetyl CoA carboxylase (ACCase) and acetolactate synthase (ALS) [8,9]. Therefore, A. myosuroides is considered one of the most troublesome weed species in Europe. Effective control of $A$. myosuroides is necessary to maintain the productivity of arable farming. 
Pre-emergence herbicides (e.g., Prosulfocarb (HRAC N/15), flufenacet (HRAC K3/15) or pendimethalin (HRAC K1/3)) are less affected by resistance [10]. However, their activity depends on sufficient soil moisture content to guarantee herbicide uptake via the roots. Flufenacet showed high efficacy against $A$. myosuroides populations that were resistant to PSII-, ACCase- and ALS-inhibitors. It inhibits the synthesis of the very long chained fatty acids (VLCFA) in the endoplasmic reticulum by disrupting the elongation process of the fatty acids [11,12]. Previous studies have confirmed resistance to flufenacet in several populations of $A$. myosuroides [12,13].

The pre-emergent herbicide cinmethylin is a promising new herbicide for the control of A. myosuroides in cereals. Originally, cinmethylin was developed by the Shell Chemical Company as a herbicide against grass weeds in rice [4]. Since 2018, the mode of action of cinmethylin could be clarified: it inhibits the fatty acid thioesterases (FAT) in the plastid [14]. Thus, the transfer of fatty acid from the plastid to the endoplasmic reticulum is disturbed in sensitive plants [14]. Similar to other pre-emergent herbicides, it is absorbed predominantly by the roots of the plants. It is most effective against problematic grass weeds such as A. myosuroides, Apera spica-venti and Lolium spp. in winter cereals [15]. Since cinmethylin has not been used in Europe and acts with a new mode of action, it is assumed that A. myosuroides are still susceptible to this herbicide.

A sustainable resistance management requires the implementation of various measures, including a regular monitoring of the fields and investigations on the reason of any poor control. Quick and reliable sensitivity tests are necessary, to confirm putative resistance and allow for an adequate adaptation of the weed control strategy. Pre-emergence herbicides have certain requirements for their environment. Therefore, testing of soil acting herbicides is sophisticated and needs specific methods and a considered interpretation of the results [13].

The most common herbicide resistance test is the whole plant pot bioassay in the greenhouse [16]. Mature seeds of plants that survived regular herbicide applications are collected in the field. After primary dormancy has been broken, seeds, as well as a sensitive biotype, are sown in pots filled with soil and treated with different dosages of herbicides. After 14 and 28 days, visual assessments of herbicide efficacy are carried out. Optionally, the fresh or dry matter is also recorded $[8,16]$. The whole plant pot bioassay is time- and space-consuming and labor-intensive $[17,18]$. Another seed based method for the detection of resistance is a petri dish assay $[19,20]$. A less widespread test is a pollen bioassay [21]. However, there are also a range of tests which generate results more quickly, such as the enzyme based test of Reade and Cobb [18], which focuses on the increased activity and abundance of glutathione-S-transferase or the Syngenta Quick-Test [22]. An agar based method for post-emergence herbicides, called Syngenta 'RISQ' test was published by [17]. This test is described as a 'Resistance In-Season Quick' test, where grass seedlings are grown on herbicide-containing agar. Visual assessment occurs 10 days after transplanting. Furthermore, the results of the whole plant pot bioassay depend on many factors, such as soil properties $(\mathrm{pH}$, organic matter and clay content), temperature regimes, and irrigation, which determine the bioavailability of herbicides $[13,16]$ which do not always deliver consistent results.

Also, baseline sensitivity data can be created prior to the initial introduction of a herbicide active ingredient, which helps to evaluate changes in sensitivity to the herbicide and thus the early detection of resistance development [23]. However, cross-resistance may also exist for new herbicides due to existing resistance mechanisms affecting new molecules [23,24]. The baseline sensitivity describes the variation of the sensitivity of different accessions, and could provide information as to whether the new active substance cinmethylin is affected by existing resistance mechanisms.

Therefore, the objective was to develop a new and quick sensitivity test system for two pre-emergent herbicides (flufenacet and cinmethylin), allowing the detection of putative resistance. We hypothesize that (i) the agar bioassay sensitivity test is faster than the whole plant pot bioassay, (ii) the new agar bioassay sensitivity test will deliver similar herbicide 
resistance factors (RFs) to the whole plant pot bioassay, and (iii) the results of both test systems are more consistent for cinmethylin than for flufenacet.

\section{Materials and Methods}

Four experiments were carried out in spring 2019: two whole plant pot bioassays in the greenhouse and two agar tests in the laboratory inside a climate chamber under controlled environmental conditions.

\subsection{Origin of the Seed Samples}

Seed samples of 18 A. myosuroides populations (Sens, A-Q) were tested and compared with each other. Seed samples of $11 \mathrm{~A}$. myosuroides populations (A-L) were collected from 11 fields located in Southwest Germany in the region of Stuttgart $\left(48^{\circ} 47^{\prime} \mathrm{N}, 9^{\circ} 11^{\prime} \mathrm{O}\right)$, Karlsruhe $\left(49^{\circ} 0^{\prime} \mathrm{N}, 8^{\circ} 24^{\prime} \mathrm{O}\right)$ and Tübingen $\left(48^{\circ} 31^{\prime} \mathrm{N}, 9^{\circ} 3^{\prime} \mathrm{O}\right)$ whereby flufenacet products were applied in at least three cropping seasons before seed harvest, according to field history data. The populations A-J were suspicious of increased tolerance against flufenacet. The seed samples of the populations $\mathrm{K}$ and $\mathrm{L}$ are from fields without any herbicide resistance problems.

The populations $\mathrm{O}-\mathrm{Q}$ originated from BASF Germany, and showed reduced sensitivity to flufenacet. These seed samples were collected from fields in Southwest Germany in the region of the Limburgerhof $\left(49^{\circ} 25^{\prime} \mathrm{N}, 8^{\circ} 24^{\prime} \mathrm{O}\right)$.

The selected populations were compared with samples of three commercially available populations, including a multi-resistant population of $\mathrm{M}$, as well as the resistant population of $\mathrm{N}$ and the population Sens, which is commonly used as a sensitive population for resistance testing with ALS-, ACCase- and VLCFA inhibitors. These seeds were purchased from Herbiseed Ltd., Berkshire, UK Seeds.

All seed samples from fields were collected by the end of June in 2017 and 2018. Therefore, within each field, 30 seeds were randomly chosen $A$. myosuroides plants were collected and stored in a paper bag at $7^{\circ} \mathrm{C}$.

\subsection{Determination of Discriminating Rates of Herbicides}

For the conducted whole plant pot bioassay in the greenhouse, the discriminating herbicide doses were determined based on the max. field dose rates of cinmethylin $\left(500 \mathrm{~g}\right.$ a.i. ha $\left.{ }^{-1}\right)$ and flufenacet $\left(250 \mathrm{~g}\right.$ a.i. $\left.\mathrm{ha}^{-1}\right)$. Dose-response tests were conducted for the agar bioassay sensitivity test to define the herbicide concentrations that best correlated with the discrimination rates of cinmethylin and flufenacet in the whole plant pot tests. First, the growth of the standard-sensitive A. myosuroides population Sens was tested at a wide range of herbicide concentrations ( $2 \mathrm{nmol}$ a.i. $\mu \mathrm{L}-0.002 \mathrm{nmol}$ a.i. $\mu \mathrm{L}^{-1}$ ). After this primary screening, a tighter range of herbicide concentrations were tested with populations of $\mathrm{L}$ and $\mathrm{N}$. These tests were repeated, and the herbicide concentrations were further reduced until discriminating herbicide concentrations were found. A discriminating concentrations is the concentration of herbicide that gives the greatest vertical discrepancy between the dose-response curves of the $\mathrm{R}$ and $\mathrm{S}$ biotypes [16]. Finally, at a concentration of $0.24 \mathrm{pmol}$ a.i. $\mathrm{uL}^{-1}$, all A. myosuroides plants should be controlled by the appropriate herbicide.

\subsection{Whole Plant Pot Bioassay in Greenhouse}

Dose response studies with seeds of all 18 A. myosuroides populations were implemented in a greenhouse whole plant pot bioassay. To achieve a uniform seedling density, germination tests were performed prior to the greenhouse trial. According to the germination test, $10-84$ seeds were sown to gain a density of 10 plants per pot. All of the seed samples were sown in compostable pots with an edge length of $8 \mathrm{~cm}\left(512 \mathrm{~cm}^{3}\right)$, filled up with a soil substrate containing $60 \%$ silt, $11.3 \%$ sand, and $28.7 \%$ clay with a $C$ content of $2.3 \%$. Seeding depth was $2 \mathrm{~cm}$. Herbicides were applied five days after seeding. All populations were treated with flufenacet $\left(\mathrm{Cadou}^{\circledR} \mathrm{SC}, 508.8 \mathrm{~g}\right.$ a.i. $\mathrm{L}^{-1}$, Bayer AG, Syngenta, 
Maintal, Germany) and cinmethylin (750 g a.i. $\mathrm{L}^{-1}$, BASF SE). Plants were treated with nine different dosages $\left(0.00 ; 3.91 ; 7.81 ; 15.63 ; 31.25 ; 62.5 ; 125 ; 250 ; 500 ; 1000 \mathrm{~g}\right.$ a.i. $\mathrm{L}^{-1}$ flufenacet $)$ $\left(0.00 ; 3.87 ; 7.73 ; 15.47 ; 30.94 ; 61.88 ; 123.75 ; 247.5 ; 495 ; 990 \mathrm{~g}\right.$ a.i. ha $^{-1}$ cinmethylin $)$ including a control, treated with water only. Herbicide treatment was carried out with a precision application chamber using a single flat fan nozzle (8002 EVS, TeeJet Spraying Systems Co., Wheaton, IL, USA, pressure $300 \mathrm{kPa}$, water amount $200 \mathrm{~L} \mathrm{ha}^{-1}$, speed $700 \mathrm{~mm} \mathrm{~s}^{-1}$ ). The pots were arranged in a randomized complete block design with three repetitions per treatment. In total, $30 \mathrm{~A}$. myosuroides plants per herbicide and dosage were treated. All of the $A$. myosuroides plants were cultivated in the greenhouse for 33 days with a $16 \mathrm{~h}$ photoperiod at $18{ }^{\circ} \mathrm{C}$ and an $8 \mathrm{~h}$ dark period at $10{ }^{\circ} \mathrm{C}$ and a humidity of $55 \%$. For illumination, sodium vapor lamps $(400 \mathrm{~W})$ were used. Visual assessment of herbicide efficacy damage was carried out 14 days and 28 days after treatment, compared to the untreated control. After 28 days above ground, biomass was harvested at soil level and dried at $80{ }^{\circ} \mathrm{C}$ for $72 \mathrm{~h}$. Afterwards dry matter content has been determined.

\subsection{Agar Bioassay Sensitivity Test}

Eighteen different $A$. myosuroides populations were tested for sensitivity to the active ingredients of flufenacet and cinmethylin in an agar bioassay sensitivity test. Experimental design was a randomized complete block design with four repetitions per treatment. To get $40 \mathrm{~A}$. myosuroides plants per herbicide and dosage, 10 germinated seeds of each biotype were transferred to one plastic tray. To ensure homogenous growth stage and reduce variation due to dormancy and numb seeds, pre-germinated seedlings were transplanted. Therefore, $A$. myosuroides seeds were pre-germinated on a moist filter paper in a climate chamber with a $16 \mathrm{~h}$ photoperiod at $18^{\circ} \mathrm{C}$ and an $8 \mathrm{~h}$ dark period at $10^{\circ} \mathrm{C}$. After 5 days, seeds had a coleoptile of around $2 \mathrm{~mm}$ (BBCH 05-09) (Figure 1A). For the agar bioassay sensitivity test, plastic trays with an edge length of $11 \times 11 \mathrm{~cm}$ and a height of $6 \mathrm{~cm}$ were prepared with $200 \mathrm{~g}$ of fire dried quartz sand $(0.7-1.2 \mathrm{~mm})$. The germinated seeds were transferred and placed with the help of a tweezer on the dry sand in the plastic trays (Figure 1B).

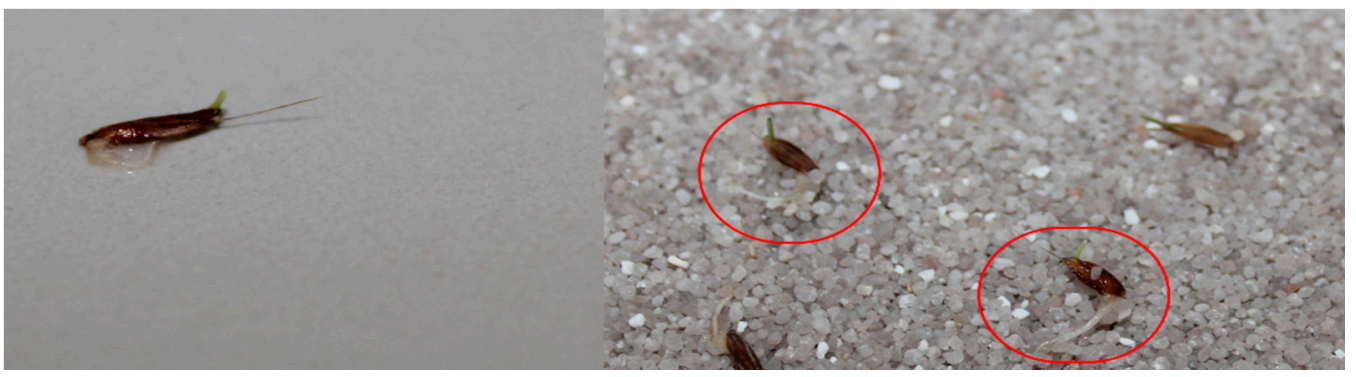

(A)

(B)

Figure 1. State of development of the A. myosuroides seed at the time of transplantation (A). Seeds were placed with the shot upwards on the sand (B).

All populations were tested over a range of seven concentrations for flufenacet 0 ; $0.004 ; 0.008 ; 0.01 ; 0.03 ; 0.06 ; 0.24$ pmol a.i. $\mathrm{uL}^{-1}$ and for cinmethylin $0 ; 0.008 ; 0.02 ; 0.03$; $0.06 ; 0.12 ; 0.24$ pmol a.i. $\mathrm{uL}^{-1}$. The control was treated with water only. For herbicide application, agar-herbicide pads were prepared right before usage. One agar pad included $25 \mathrm{~mL}$ of distilled water mixed with the related amount of herbicide. Furthermore 25 $\mathrm{mL}$ of $60{ }^{\circ} \mathrm{C}$ warm agar solution (3.2\% agar) (European type, CHEMSOLUTE, Renningen, Germany) and $0.05 \%$ of a nutrient solution ( $8 \%$ nitrogen, $8 \%$ phosphate and $6 \%$ potassium) were added and mixed homogenously. The final mixture was poured into a form with a size of $11 \times 11 \mathrm{~cm}$ to generate equal sized pads with a height of $1 \mathrm{~cm}$ (Figure 2 ). After cooling down, the pads were inserted into the already prepared plastic trays with the seeds. The pads were placed with direct contact to the germinated plants (Figure 3). At the end, every plastic tray was covered with a transparent lid All trays were placed for 7 days in a 
climate chamber at a temperature of $20^{\circ} \mathrm{C}$, with $12 \mathrm{~h}$ of illumination $\left(24 \mathrm{~W} \mathrm{~m}^{-2}\right)$ (Figure 4). After 7 days above ground, biomass was harvested at soil level and dried at $80{ }^{\circ} \mathrm{C}$ for $72 \mathrm{~h}$. Afterwards, dry matter content has been determined.

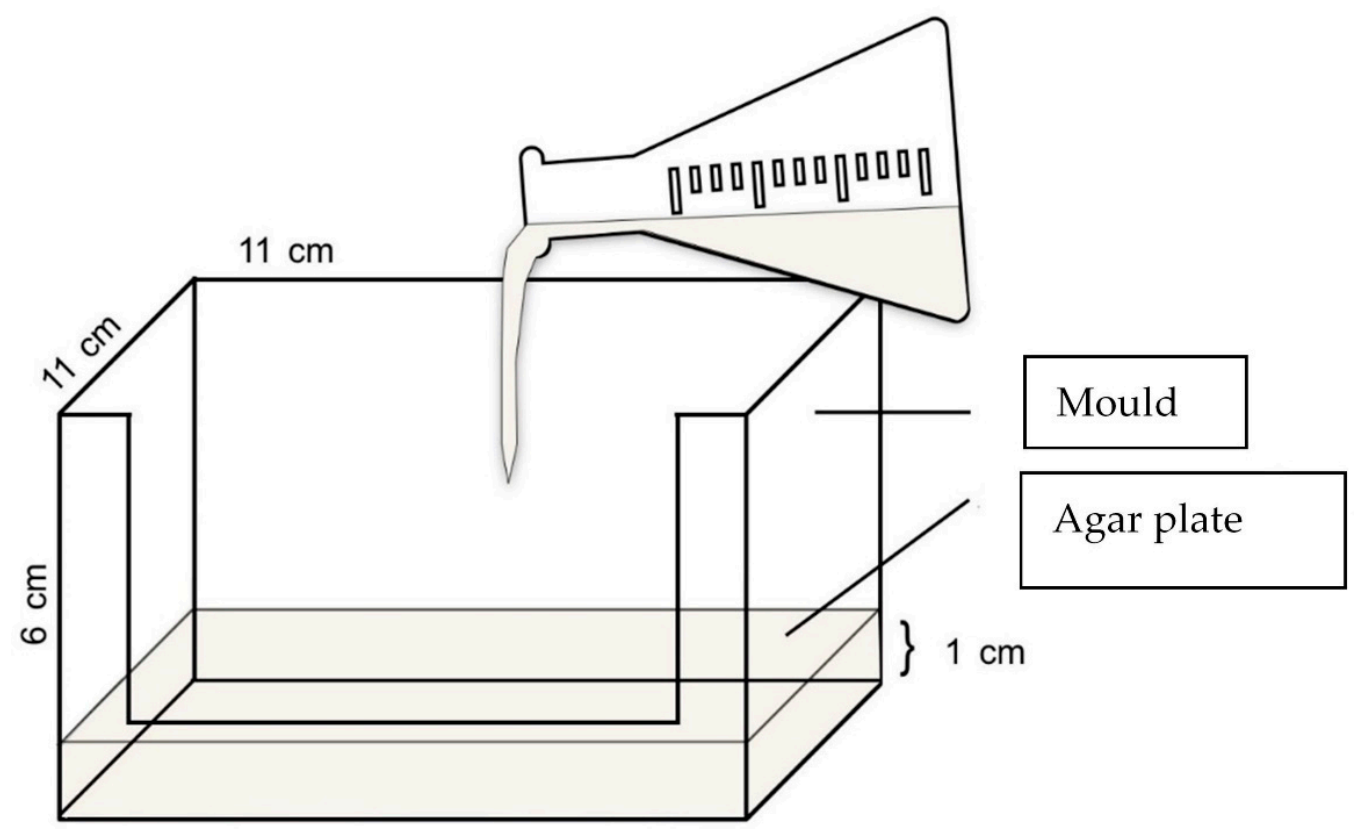

Figure 2. A schematic drawing of the mold for agar herbicide plates.

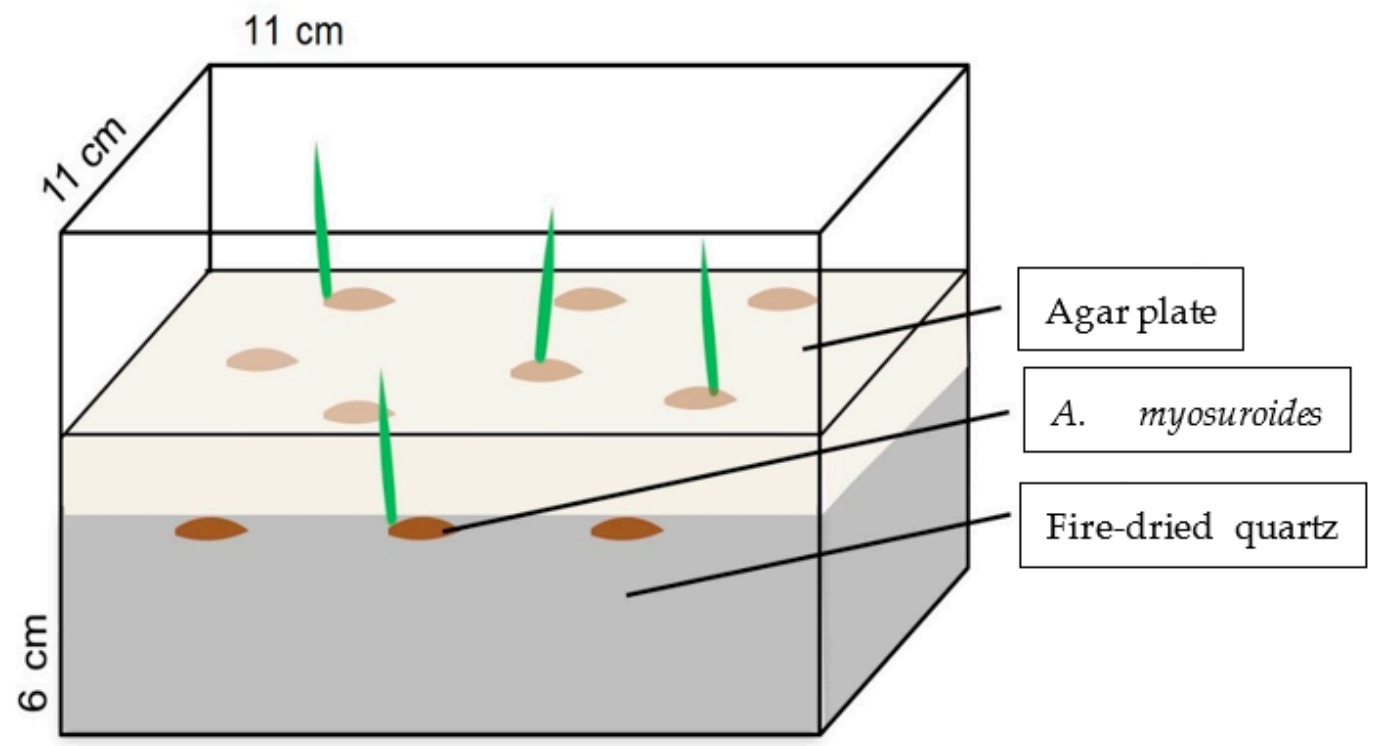

Figure 3. Structure of the agar test: 1 st layer = fire-dried quartz sand.; 2 nd layer $=$ pre-germinated A. myosuroides seeds; 3rd layer = agar plate consisting of agar, herbicide and nutrients.

\subsection{Statistical Analysis}

Dose-response assays to characterize the resistance levels of flufenacet and cinmethylin were analyzed as randomized block designs. The data were analyzed with the statistical software R Studio (Version 3.6.2, RStudio Team, Boston, MA, USA). To illustrate differences of herbicide sensitivity between populations, the $\mathrm{R}$ package drc was used to calculate dose response curves (DRC) and ED50 values for each $A$. myosuroides population and herbicide treatment based on relative dry matter (Version 3.0-1) [25]. To determine the response of 18 A. myosuroides populations to different dose rates of flufenacet and cinmethylin, only populations without significant differences (based on $95 \%$ confidence intervals) between the two experiments conducted in the greenhouse and the climate chamber were included in 
the analysis. DRCs were calculated with a three parametric log-logistic model (1) according to [26].

$$
\mathrm{Y}=\mathrm{c}+\frac{\mathrm{D}-\mathrm{C}}{1+\exp \left(\mathrm{b} \ln \left(\frac{\mathrm{x}}{\mathrm{ED} 50}\right)\right)}
$$

where $\mathrm{Y}$ represents the plant response (relative dry matter content $(\mathrm{g})$ ), $\mathrm{D}$ is the upper limit of the curve, $\mathrm{C}$ is the lower Limit and $\mathrm{b}$ is proportional to the slope around ED50, the dose at which the plant response is reduced by $50 \%$. Shifts of the dose-response curves were horizontally assessed by F-test, $(\alpha=0.05)$. In all evaluations, a model lack of fit test was performed [27]. Finally, the herbicide resistance factor (RF) was calculated:

$$
\mathrm{RF}=\frac{\mathrm{ED} 0_{\text {test biotype }}}{\mathrm{ED} 0_{\text {standard }}}
$$

where ED50, as mentioned above, is the herbicide dosage causing $50 \%$ reduction in the plant response [27].

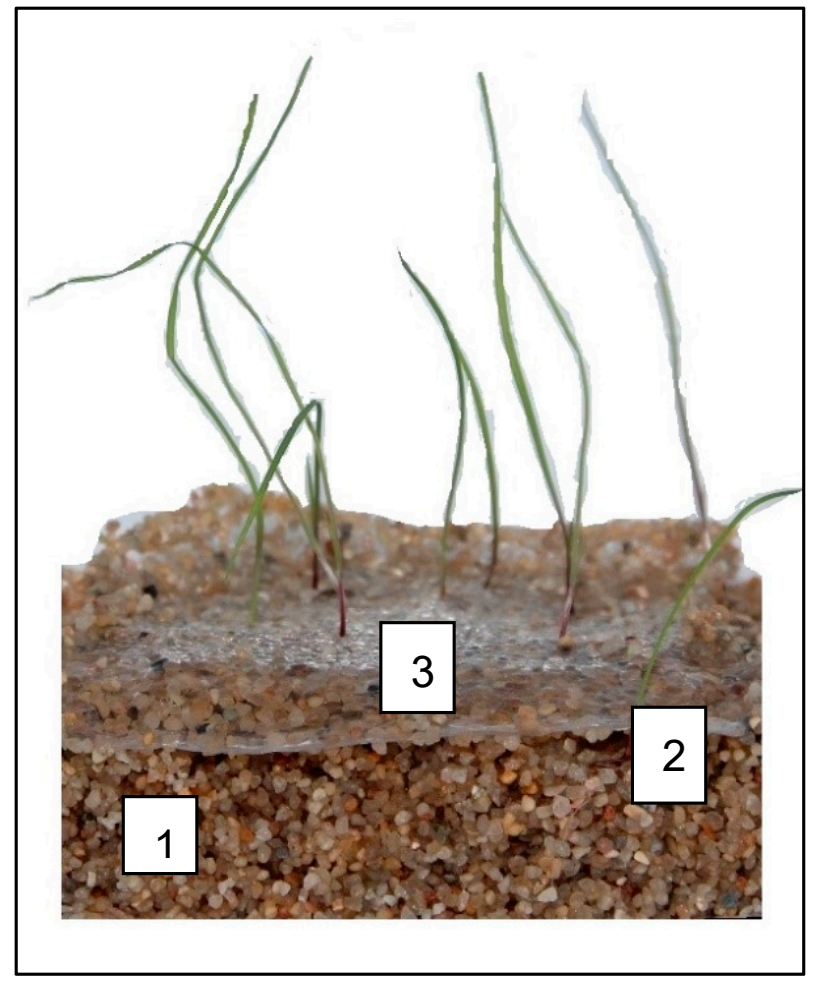

Figure 4. Structure of the agar test: 1 st layer = fire-dried quartz sand; 2 nd layer = pre-germinated A. myosuroides seeds; 3 rd. layer $=$ agar plate consisting of agar, herbicide and nutrients. Plants showed in the picture are from the sensitive standard treated with no herbicide, 7 days after transplanting.

\section{Results}

\subsection{ED50 Values and Resistance Factors-Cinmethylin}

In the whole plant bioassay, the susceptible A. myosuroides standard (Sens) showed for cinmethylin a $50 \%$ definite reduction in relative dry matter at $10.05 \mathrm{~g}$ a.i. ha ${ }^{-1}$ in the first experiment (V1) and at the second (V2) $15.32 \mathrm{~g}$ a.i. ha ${ }^{-1}$. For population F the ED50 V2 value was increased by $211 \%\left(265.04 \mathrm{~g}\right.$ a.i. $\mathrm{ha}^{-1}$ ) compared with V1. The calculated resistance factor (RF) for population F in V1 was 8.5 and for V2, 17.3. Population J showed an increased ED50 value in V2 by $67 \%$ (250.48 $\mathrm{g}$ a.i. ha ${ }^{-1}$ ) compared to V1. Therefore, an $\mathrm{RF}$ of 14.95 was calculated in $\mathrm{V} 1$ and 16.35 for $\mathrm{V} 2$. The $50 \%$ reduction in relative dry matter content in all of the other populations ranged between $1.5 \mathrm{~g}$ a.i. ha ${ }^{-1}$ until $48.68 \mathrm{~g}$ a.i. ha ${ }^{-1}$ in V1 and $0.5 \mathrm{~g}$ a.i. ha ${ }^{-1}$ until $59.29 \mathrm{~g}$ a.i. ha ${ }^{-1}$ in V2. V1 and V2 in the greenhouse did not differ significantly from each other (Table 1 ). 
Table 1. Evaluation of sensitivity of the A. myosuroides populations to cinmethylin in a whole plant pot bioassay in greenhouse and agar based resistance test under controlled environmental conditions in a climate chamber. ED50 = herbicide dosage causing 50\% reduction in the relative dry matter content and RF = resistance factor. V1 = experiment one, $\mathrm{V} 2=$ experiment 2 . Whole plat pot bioassay V1: lack-of-fit, $p=0.03$; V2: lack-of-fit, $p=0.02$; Agar bioassay sensitivity test V1: lack-of-fit, $p=0.005$; V2: lack-of-fit, $p=0.003$.

\begin{tabular}{|c|c|c|c|c|c|c|c|c|}
\hline \multicolumn{9}{|l|}{ Cinmethylin } \\
\hline \multirow{3}{*}{ Population } & \multicolumn{4}{|c|}{ Whole Plant Pot Bioassay } & \multicolumn{4}{|c|}{ Agar Bioassay Sensitivity Test } \\
\hline & ED50 V1 & ED50 V2 & RF V1 & RF V2 & ED50 V1 & ED50 V2 & RF V1 & RF V2 \\
\hline & \multicolumn{2}{|c|}{ g a.i. ha ${ }^{-1}$} & \multicolumn{6}{|c|}{ pmol a.i. $L^{-1}$} \\
\hline Sens & 10.05 & 15.32 & 1.00 & 1.00 & 0.22 & 0.20 & 1.00 & 1.00 \\
\hline A & 13.57 & 19.15 & 1.35 & 1.25 & 0.10 & 0.17 & 0.44 & 0.78 \\
\hline $\mathrm{B}$ & 14.48 & 30.64 & 1.45 & 2.00 & 0.30 & 0.34 & 1.34 & 1.56 \\
\hline $\mathrm{C}$ & 19.20 & 30.33 & 1.91 & 1.98 & 0.10 & 0.09 & 0.46 & 0.40 \\
\hline $\mathrm{D}$ & 11.48 & 17.31 & 1.14 & 1,13 & 0.19 & 0.18 & 0.84 & 0.84 \\
\hline $\mathrm{E}$ & 35.55 & 59.29 & 3.54 & 3.87 & 1.35 & 0.35 & 2.20 & 1.60 \\
\hline $\mathrm{F}$ & 85.20 & 265.04 & 8.50 & 17.30 & 1.37 & 0.55 & 7.12 & 2.50 \\
\hline G & 12.08 & 26.04 & 1.20 & 1.70 & 0.88 & 0.24 & 0.33 & 1.10 \\
\hline $\mathrm{H}$ & 48.68 & 53.62 & 4.85 & 3.50 & 1.11 & 0.33 & 3.75 & 1.50 \\
\hline I & 17.33 & 28.65 & 1.73 & 1.87 & 1.01 & 0.22 & 0.72 & 1.00 \\
\hline $\mathrm{J}$ & 150.00 & 250.48 & 14.95 & 16.35 & 0.79 & 0.28 & 14.16 & 1.26 \\
\hline $\mathrm{K}$ & 20.70 & 29.57 & 2.06 & 1.93 & 1.25 & 0.28 & 0.81 & 1.25 \\
\hline $\mathrm{L}$ & 35.58 & 59.29 & 3.54 & 3.87 & 0.30 & 0.32 & 1.35 & 1.6 \\
\hline $\mathrm{M}$ & 10.52 & 7.05 & 1.04 & 0.46 & 0.08 & 0.264 & 0.36 & 1.2 \\
\hline $\mathrm{N}$ & 38.76 & 26.50 & 3.86 & 1.73 & 0.16 & 0.33 & 0.72 & 1.5 \\
\hline $\mathrm{O}$ & 32.78 & 22.37 & 3.26 & 1.46 & 0.06 & 0.4026 & 0.27 & 1.83 \\
\hline $\mathrm{P}$ & 1.5 & 0.50 & 0.15 & 0 & 0.23 & 0.319 & 1.04 & 1.45 \\
\hline $\mathrm{Q}$ & 3.21 & 2.14 & 0.32 & 0.14 & 0.08 & 0.099 & 0.36 & 0.45 \\
\hline
\end{tabular}

The susceptible $A$. myosuroides population in the agar bioassay sensitivity test showed a $50 \%$ reduction in relative dry matter content at 0.22 pmol a.i. $\mu \mathrm{L}^{-1}$ in $\mathrm{V} 1$ and $0.20 \mathrm{pmol}$ a.i. $\mu \mathrm{L}^{-1}$ in V2. The population of F showed an increased ED50 value of 1.37 pmol a.i. $\mu \mathrm{L}^{-1}$ in V1 compared to the ED50 value of $0.55 \mathrm{pmol}$ a.i. $\mu \mathrm{L}^{-1}$ in $\mathrm{V} 2$. The calculated $\mathrm{RF}$ for population $\mathrm{F}$ was 7.12 in $\mathrm{V} 1$ and 2.5 in V2. The population J showed a similar response to cinmetyhlin, with 0.79 pmol a.i. $\mu \mathrm{L}^{-1}$ in $\mathrm{V} 1$ and 0.27 pmol a.i. $\mu \mathrm{L}^{-1}$ in V2. The calculated RF for population J in the V1 was 14.16 and for V2 1.26. The ED50 values of the other populations for cinmethylin varied between $0.06 \mathrm{pmol}$ a.i. $\mu \mathrm{L}^{-1}$ until 1.35 pmol a.i. $\mu \mathrm{L}^{-1}$ (RF $0.27-2.2$ ) in V1 and 0.08 pmol a.i. $\mu \mathrm{L}^{-1}$ until 0.40 pmol a.i. $\mu \mathrm{L}^{-1}$ (RF 0.4-1.83) for theV2. There were no significant differences for cinmethylin between experiment one and two in the agar bioassay sensitivity test (Table 1 ).

\subsection{ED50 Values and Resistance Factors-Flufenacet}

The whole plant pot bioassay for flufenacet resulted in an ED50 value of $23.8 \mathrm{~g}$ a.i. ha ${ }^{-1}$ for V1 and $10.5 \mathrm{~g}$ a.i. $\mathrm{ha}^{-1}$ for V2. The A. myosuroides population $\mathrm{Q}$ showed a reduction of the ED50 value by $85 \%$ in V2 compared to V1. The calculated RF for population Q in V1 was 13.46 and for V2 17.51. The populations $\mathrm{N}, \mathrm{O}$ and $\mathrm{P}$ showed a lower ED50 value in V1 (12.5 g a.i. ha ${ }^{-1}, 71.62 \mathrm{~g}$ a.i. $\mathrm{ha}^{-1}, 222.76 \mathrm{~g}$ a.i. $\left.\mathrm{ha}^{-1}\right)$ compared to V2 (63.74 g a.i. ha ${ }^{-1}$, 231.42 $\mathrm{g}$ a.i. $\mathrm{ha}^{-1}, 428.61 \mathrm{~g}$ a.i. $\mathrm{ha}^{-1}$ ). The corresponding RFs for the populations $\mathrm{N}, \mathrm{O}$ and $\mathrm{P}$ were in V1 0.53, 3.01 and 9.36 and in V2 6.07, 22.04 and 40.82. The ED50 values of the other populations for flufenacet varied between $5.1 \mathrm{~g}$ a.i. ha ${ }^{-1}$ up to $200.65 \mathrm{~g}$ a.i. ha ${ }^{-1}$ (RF $0.22-8.44$ ) in V1 and $4.31 \mathrm{~g}$ a.i. ha ${ }^{-1}$ up to $80.43 \mathrm{~g}$ a.i. $\mathrm{ha}^{-1}$ (RF 0.41-7.66) in V2. There were no significant differences for flufenacet between V1 and V2 in the bioassay test (Table 2). 
Table 2. Evaluation of sensitivity of the A. myosuroides populations to flufenacet in a whole plant pot bioassay in greenhouse and agar based resistance test under controlled environmental conditions in a climate chamber. Whereas ED50 = herbicide dosage causing $50 \%$ reduction in the relative dry matter content and RF = sensitivity factor. Whole plat pot bioassay V1: lack-of-fit, $p=0.99$; V2: lack-of-fit, $p=0.95$; Agar test V1: lack-of-fit, $p=0.91$; V2: lack-of-fit, $p=0.92$.

\begin{tabular}{|c|c|c|c|c|c|c|c|c|}
\hline \multicolumn{9}{|l|}{ Figure } \\
\hline \multirow{3}{*}{ Population } & \multicolumn{4}{|c|}{ Whole Plant Pot Bioassay } & \multicolumn{4}{|c|}{ Agar Bioassay Sensitivity Test } \\
\hline & ED50 V1 & ED50 V2 & RF V1 & RF V2 & ED50 V1 & ED50 V2 & RF V1 & RF V2 \\
\hline & \multicolumn{2}{|c|}{ g a.i. ha ${ }^{-1}$} & \multicolumn{6}{|c|}{ pmol a.i. $L^{-1}$} \\
\hline Sens & 23.80 & 10.50 & 1.00 & 1.00 & 0.04 & 0.07 & 1.00 & 1.00 \\
\hline $\mathrm{A}$ & 5.65 & 4.73 & 0.24 & 0.45 & 0.50 & 0.93 & 12.92 & 13.24 \\
\hline $\mathrm{B}$ & 26.20 & 22.05 & 1.10 & 2.10 & 0.50 & 0.74 & 12.07 & 10.57 \\
\hline $\mathrm{C}$ & 5.10 & 9.35 & 0.22 & 0.89 & 0.60 & 0.90 & 13.56 & 12.86 \\
\hline $\mathrm{D}$ & 26.35 & 27.62 & 1.11 & 2.63 & 0.59 & 0.81 & 13.22 & 11.5 \\
\hline $\mathrm{E}$ & 64.35 & 38.22 & 2.70 & 3.64 & 0.26 & 0.30 & 5.71 & 4.23 \\
\hline $\mathrm{F}$ & 200.65 & 80.43 & 8.44 & 7.66 & 0.04 & 0.07 & 0.99 & 1.02 \\
\hline G & 66.55 & 47.88 & 3.25 & 4.56 & 0.28 & 0.30 & 6.34 & 4.29 \\
\hline $\mathrm{H}$ & 52.50 & 38.75 & 2.21 & 3.69 & 0.60 & 1.02 & 13.40 & 14.55 \\
\hline I & 0.29 & 68.67 & 6.00 & 6.54 & 0.05 & 0.09 & 1.13 & 1.25 \\
\hline $\mathrm{J}$ & 142.45 & 76.86 & 6.10 & 7.32 & 0.62 & 0.88 & 13.40 & 12.60 \\
\hline $\mathrm{K}$ & 11.00 & 5.46 & 0.46 & 0.52 & 0.04 & 0.00 & 1.00 & 1.01 \\
\hline $\mathrm{L}$ & 7.55 & 4.31 & 0.31 & 0.41 & 0.05 & 0.08 & 1.25 & 1.20 \\
\hline $\mathrm{M}$ & 36.51 & 19.95 & 1.50 & 1.90 & 0.11 & 0.59 & 2.75 & 8.40 \\
\hline $\mathrm{N}$ & 12.50 & 63.74 & 0.53 & 6.07 & 0.03 & 0.45 & 0.75 & 6.45 \\
\hline $\mathrm{O}$ & 71.62 & 231.42 & 3.01 & 22.04 & 0.47 & 1.49 & 11.75 & 21.30 \\
\hline $\mathrm{P}$ & 222.76 & 428.61 & 9.36 & 40.82 & 0.55 & 2.56 & 13.75 & 36.56 \\
\hline $\mathrm{Q}$ & 320.46 & 48.195 & 13.46 & 17.51 & 0.10 & 0.32 & 2.50 & 4.59 \\
\hline
\end{tabular}

The susceptible $A$. myosuroides population in the agar bioassay sensitivity test showed for flufenacet a $50 \%$ reduction in relative dry matter content at 0.04 pmol a.i. $\mu \mathrm{L}^{-1}$ in V1 and 0.07 pmol a.i. $\mu \mathrm{L}^{-1}$ in V2. The populations of $\mathrm{M}, \mathrm{N}, \mathrm{O}$ and P showed lower ED50 values of 0.11 pmol a.i. $\mu \mathrm{L}^{-1}, 0.03$ pmol a.i. $\mu \mathrm{L}^{-1}, 0.47$ pmol a.i. $\mu \mathrm{L}^{-1}, 0.55$ pmol a.i. $\mu \mathrm{L}^{-1}$ in V1 compared to the ED50 values of 0.59 pmol a.i. $\mu \mathrm{L}^{-1}, 0.45$ pmol a.i. $\mu \mathrm{L}^{-1} ; 1.49$ pmol a.i. $\mu \mathrm{L}^{-1} ; 2.56 \mathrm{pmol}$ a.i. $\mu \mathrm{L}^{-1}$ in $\mathrm{V} 2$. The calculated $\mathrm{RF}$ for the populations $\mathrm{M}, \mathrm{N}, \mathrm{O}$ and $\mathrm{P}$ were in $\mathrm{V} 1,2.75,0.75,11.75,13.75$, and in $\mathrm{V} 2$ following RFs were calculated as 8.4, 6.45, 21.3, and 36.56. The ED50 values of the other populations for flufenacet varied between 0.04 pmol a.i. $\mu \mathrm{L}^{-1}$ up to 0.62 pmol a.i. $\mu \mathrm{L}^{-1}$ (RF 1-13.4) in V1 and 0.05 pmol a.i. $\mu \mathrm{L}^{-1}$ up to $1.02 \mathrm{pmol}$ a.i. $\mu \mathrm{L}^{-1}$ (RF 1.0-14.55) in V2. There were no significant differences for flufenacet between V1 and V2 in the agar bioassay sensitivity test (Table 2).

\section{Discussion}

Pre-emergence testing of herbicides presents numerous challenges. The efficacy of pre-emergent herbicides is affected by soil moisture, soil structure, seed depth, dormancy, germination rate, and time. Their bioavailability also depends on soil properties such as $\mathrm{pH}$, organic matter, and clay content [16]. Current whole plant bioassay test systems, especially for pre-emergence herbicides, require a large investment of resources (space, manpower) and time. To find a standard method for validating pre-emergence herbicide resistance, this study compared the conventional whole plant pot bioassay with a newly developed agar bioassay sensitivity test. For this purpose, the two active ingredients flufenacet and cinmethylin were tested on $18 \mathrm{~A}$. myosuroides populations. Both active ingredients were carefully selected for this study: cinmethylin with its new mode of action on which resistance to herbicides can be assumed in the future, and flufenacet which has already shown first resistance.

The time required in the recently developed agar bioassay sensitivity test system (12 days) was reduced by 21 days, compared to whole plant pot bioassay (33 days) in the 
greenhouse $[16,18]$. Therefore, hypothesis (i), that the agar bioassay sensitivity test is faster than the whole plant pot bioassay, can be accepted. In comparison, the Syngenta RISQ test provides valid results within 10 days, but the time of pre-germination of the seeds has to be added [17]. A quick overview of the resistance status is also provided by the Rothamsted Rapid Resistance Test, which delivers results within 14 days [19]. Especially, the whole plant pot bioassay requires a lot of time for mixing the soil. Particularly with regard to testing systems dealing with pre-emergence herbicides, the composition of the soil plays a major role. Soil properties such as $\mathrm{pH}$, organic matter content and clay content determine the bioavailability of herbicides $[13,16]$. Therefore, potting mixtures are not suitable for whole plant pot bioassays and it is necessary to mix its own soil. Alternatively, the common soil substrate was exchanged by an agar medium. The exchange was intended to reduce the influence of soil parameters on the herbicide availability. This reduction of environmental factors could not be confirmed by our tests. However, the agar medium did also not increase the reliability of resistance detection. In summary, it can be assumed that the time required for the agar bioassay sensitivity test is restricted to a few very intensive days, while the conventional greenhouse whole plant pot bioassay requires a longer period of time with a lower workload per day.

The results from the whole plant pot bioassay have been reproduced for the majority of the cinmethylin tested population in the agar bioassay sensitivity test. Nevertheless, hypotheses two needs to be rejected. The discrepancy between the two tests was striking for the populations $\mathrm{F}, \mathrm{J}, \mathrm{K}$ for cinmethylin and was expected of the populations $\mathrm{E}, \mathrm{G}$, $\mathrm{K}, \mathrm{L}$ and $\mathrm{N}$ for flufenacet. Almost all RFs from the whole plant pot bioassay are lower in the agar bioassay sensitivity test for cinmethylin, while for flufenacet overall, they increased with more variation. Same weed-species populations might express different levels of sensitivity to a specific herbicide. This variation can be investigated in whole plant bioassays, described as baseline sensitivity testing before a new herbicide is introduced into the market. Previous attempts have already shown that weed populations can vary greatly in susceptibility to a herbicide and experimental conditions [28,29]. Minor differences in ED50 values between biotypes are naturally occurring [24]. Cinmethylin is a new active substance not yet marketed in Europe and never used for the control of $A$. myosuroides [4]. For cinmethylin, resistance factors ranged between one and three, with the exception of three biotypes with partly higher resistance factors. Perhaps some populations are even more susceptible than the sensitive standard, and produced less dry matter in this case. As a result, lower resistance factors were calculated. The populations $\mathrm{F}$ and J showed reduced susceptibility to cinmethylin within both test systems. Recent studies suggest that selectivity in wheat is position-dependent, but also involves metabolism by cytochrome P450. Thus, if wheat has a CYP 450 that can degrade this herbicide, this or a similar cytochrome could also be present in A. myosuroides [30].

However, the results do not indicate resistance to cinmethylin. Out of this dataset a baseline sensitivity can be derived. According to the whole plant pot bioassay in the greenhouse, a dose of $100 \mathrm{~g}$ active ingredient (a.i.) ha- 1 of cinmethyline could be adopted as the baseline. For flufenacet, the results of the whole plant pot bioassay in the greenhouse could not be reproduced in the agar bioassay sensitivity test. Besides the genetic variability of the population, the concentration of a.i. and the application of the herbicide could probably influence the availability of the herbicides. Flufenacet is mainly taken up by the roots, and only a small amount is taken up by the leaves. In a study by Andreasen et al. [31], they tested a foliar application of flufenacet; after application and complete droplet drydown, only the crystals of the active ingredients are left on the leaf surface, which makes the herbicide unviable for foliar uptake [32]. Within this present study, herbicide was applied via the agar plate. It could be possible that a reduced rate of herbicide is taken up by the roots. In contrast to the study by Rosenhauer and Petersen [33], all plants grew through the agar and came into contact with the herbicide at least with their shoots. In the study by Rosenhauer and Petersen [33], no clear statement could be made concerning the penetration of the herbicide from the agar into the root zone. In the current study, no 
clear statement can be made on this either, as the test for cinmethylin gave valid results. Further experiments have to be conducted to test the availability of the herbicide within the root zone.

Only small concentrations are used in the agar bioassay sensitivity test. The influence of the concentration of the a.i. of the herbicide could be a factor. Little is known about this. However, the influence of a.i. concentration on pesticide uptake has been systematically studied only for glyphosate. It is now known that glyphosate uptake is closely related to its concentration in the spraying solution. The higher the a.i. concentration, the greater the uptake [34]. This may also have an influence on the results in the agar bioassay sensitivity test. On the other hand, only fragmentary information is available for some other chemicals such as cinmethylin or flufenacet.

In contrast to the $\mathrm{F}, \mathrm{J}$ and $\mathrm{Q}$ populations, the $\mathrm{A}, \mathrm{C}, \mathrm{D}$ and $\mathrm{H}$ populations showed a lower resistance factor in the agar bioassay sensitivity test compared to the whole plant pot bioassay in the greenhouse. It is possible that the herbicide was metabolized more quickly here due to higher temperatures in the greenhouse, which reduces the herbicidal effect on the plant. This phenomenon has already been observed in other trials where post-emergence herbicide was used [35]. This could result in a misinterpretation of the resistance factors in the whole plant pot bioassay trials. In order to draw reliable and precise results from the resistance test, it is important to ensure that the external factors, such as water supply and temperature, are standardized and not subject to any fluctuations. The results of this study may not be transferable to other A. myosuroides populations, but provide information on the susceptibility status in the area where the biotypes use originates [24]. However, while reduced sensitivity or resistance can often be demonstrated in the laboratory, this does not necessarily mean that weed control under field conditions will no longer take place. The term 'practical resistance' has been established, which describes the loss of weed control under field conditions due to a shift in sensitivity [36]. To interpret the results correctly, it is necessary to consider the resistance factors and the actual rate required to control the resistant population [37]. The calculated resistance factor depends on the sensitivity standard used.

The sensitivity of the biotypes was higher against cinmethylin, especially in the agar bioassay sensitivity test, than with flufenacet, which has been used for many years. In conclusion, it can be confirmed that the new agar bioassay sensitivity test has high potential to increase the test volume of samples due to the shorter test duration. Nevertheless, additional tests should be carried out to clearly confirm resistance. Especially, to increase the validity of the agar bioassay sensitivity test, further testing with more populations and pre-emergence herbicides should be conducted.

Author Contributions: M.H.M. was responsible for the experiments, conducted the statistical analysis and wrote the manuscript. A.I.L. was responsible for the experiments and revised the manuscript A.M. was responsible for data collection and revised the manuscript. B.S. revised the manuscript. R.G. supervised the experiments and revised the manuscript. All authors have read and agreed to the published version of the manuscript.

Funding: This research received no external funding.

Institutional Review Board Statement: Not applicable.

Informed Consent Statement: Not applicable.

Data Availability Statement: Data sharing not applicable.

Conflicts of Interest: Author B.S. is an employee of BASF. He was involved in the development of cinmethylin. B.S. had no role in the design of the study; in the collection, analyses, or interpretation of data; in the writing of the manuscript, or in the decision to publish the results. 


\section{References}

1. Rüegg, W.T.; Quadranti, M.; Zoschke, A. Herbicide research and development: Challenges and opportunities. Weed Res. 2007, 47, 271-275. [CrossRef]

2. Chauvel, B.; Guillemin, J.-P.; Colbach, N. Evolution of a herbicide-resistant population of Alopecurus myosuroides Huds. in a long-term cropping system experiment. Crop Prot. 2009, 28, 343-349. [CrossRef]

3. Lutman, P.J.W.; Moss, S.R.; Cook, S.; Welham, S.J. A review of the effects of crop agronomy on the management of Alopecurus myosuroides. Weed Res. 2013, 53, 299-313. [CrossRef]

4. Dayan, F.E. Current Status and Future Prospects in Herbicide Discovery. Plants 2019, 8, 341. [CrossRef]

5. Gressel, J.; Segel, L.A. Modelling the Effectiveness of Herbicide Rotations and Mixtures as Strategies to Delay or Preclude Resistance. Weed Technol. 1990, 4, 186-198. [CrossRef]

6. Hull, R.I.; Moss, S.R. Is the increasing reliance on residual herbicides for Alopecurus myosuroides (black-grass) control sustainable? Asp. Appl. Biol. 2012, 117, 25-32.

7. Heap, I. International Survey of Herbicide Resistant Weeds. Available online: http://weedscience.com/ (accessed on 18 January 2020).

8. Menne, H.J.; Hogrefe, C. (Eds.) Impact of multiple resistance mechanisms in black-grass (Alopecurus myosuroides Huds.) populations on the of cereal herbicides. In Proceedings of the 25th German Conference on Weed Biology and Weed Control, Braunschweig, Germany, 13-15 March 2012.

9. Heap, I. Global perspective of herbicide-resistant weeds. Pest Manag. Sci. 2014, 70, 1306-1315. [CrossRef]

10. Bailly, G.C.; Dale, R.P.; Archer, S.A.; Wright, D.J.; Kaundun, S.S. Role of residual herbicides for the management of multiple herbicide resistance to ACCase and ALS inhibitors in a black-grass population. Crop Prot. 2012, 34, 96-103. [CrossRef]

11. Busi, R. Resistance to herbicides inhibiting the biosynthesis of very-long-chain fatty acids. Pest Manag. Sci. 2014, 70, 1378-1384. [CrossRef]

12. Dücker, R.; Zöllner, P.; Parcharidou, E.; Ries, S.; Lorentz, L.; Beffa, R. Enhanced metabolism causes reduced flufenacet sensitivity in black-grass (Alopecurus myosuroides Huds.) field populations. Pest Manag. Sci. 2019, 75, 2996-3004. [CrossRef]

13. Menne, H.J.; Laber, B.; Kerlen, D.; Beffa, R. (Eds.) Effectiveness of flufenacet in controlling resistant black-grass (Alopecurus myosuroides Huds.)-comparison of glasshouse and field trial results. In Proceedings of the 25th German Conference on Weed Biology and Weed Control, Braunschweig, Germany, 13-15 March 2012.

14. Campe, R.; Hollenbach, E.; Kämmerer, L.; Hendriks, J.; Höffken, H.W.; Kraus, H.; Lerchl, J.; Mietzner, T.; Tresch, S.; Witschel, M.; et al. A new herbicidal site of action: Cinmethylin binds to acyl-ACP thioesterase and inhibits plant fatty acid biosynthesis. Pestic. Biochem. Physiol. 2018, 148, 116-125. [CrossRef]

15. Basf. BASF Reicht Zulassungsdossiers für Zwei Neue Herbizid-Wirkstoffe ein. Available online: https://www.basf.com/global/ de/media/news-releases/2018/06/p-18-242.html (accessed on 14 December 2020).

16. Beckie, H.J.; Heap, I.M.; Smeda, R.J.; Hall, L.M. Screening for Herbicide Resistance in Weeds 1. Weed Technol. 2000, 14, 428-445. [CrossRef]

17. Reade, J.P.H.; Cobb, A.H. New, quick tests for herbicide resistance in black-grass (Alopecurus myosuroides Huds) based on increased glutathione S-transferase activity and abundance. Pest Manag. Sci. 2002, 58, 26-32. [CrossRef]

18. Kaundun, S.S.; Hutchings, S.-J.; Dale, R.P.; Bailly, G.C.; Glanfield, P. Syngenta 'RISQ' test: A novel in-season method for detecting resistance to post-emergence ACCase and ALS inhibitor herbicides in grass weeds. Weed Res. 2011, 51, 284-293. [CrossRef]

19. Murray, B.G.; Friesen, L.F.; Beaulieu, K.J.; Morrison, I.N. A Seed Bioassay to Identify Acetyl-CoA Carboxylase Inhibitor Resistant Wild Oat (Avena fatua) Populations. Weed Technol. 1996, 10, 85-89. [CrossRef]

20. Moss, S. Rothamsted Rapid Resistance Test for Detecting Herbicide-Resistance in Annual Grass-Weeds. Available online: https://media.ahdb.org.uk/media/Default/Imported\%20Publication\%20Docs/AHDB\%20Cereals\%20\&\%20Oilseeds/Weeds / WRAG/Rothamsted\%20Rapid\%20Resistance\%20Test $\% 20 \% 20$ for $\% 20$ black-grass, \%20wild-oats $\% 20$ and $\% 20$ Italian $\% 20$ ryegrass\%20(1999).pdf (accessed on 18 January 2020).

21. Letouzé, A.; Gasquez, J. A pollen test to detect ACCase target-site resistance within Alopecurus myosuroides populations. Weed Res. 2000, 40, 151-162. [CrossRef]

22. Boutsalis, P. Syngenta Quick-Test: A Rapid Whole-Plant Test for Herbicide Resistance 1. Weed Technol. 2001, 15, 257-263. [CrossRef]

23. Ulber, L.; Nordmeyer, H.; Zwerger, P. Resistance risk assessment within herbicide authorization-A call for sensitivity data. Pest Manag. Sci. 2013, 69, 160-164. [CrossRef]

24. Espeby, L.Å.; Fogelfors, H.; Milberg, P. Susceptibility variation to new and established herbicides: Examples of inter-population sensitivity of grass weeds. Crop Prot. 2011, 30, 429-435. [CrossRef]

25. Ritz, C.; Baty, F.; Streibig, J.C.; Gerhard, D. Dose-Response Analysis Using R. PLoS ONE 2015, 10, e0146021. [CrossRef]

26. Streibig, J.C. Herbicide bioassay. Weed Res. 1988, 28, 479-484. [CrossRef]

27. Knezevic, S.Z.; Streibig, J.C.; Ritz, C. Utilizing R Software Package for Dose-Response Studies: The Concept and Data Analysis. Weed Technol. 2007, 21, 840-848. [CrossRef]

28. Ellis, M.; Kay, Q.O.N. Genetic variation in herbicide resistance in scentless mayweed (Tripleurospermum inodorum (L.) Schultz Bip.) I. Differences between populations in response to MCPA. Weed Res. 1975, 15, 307-315. [CrossRef] 
29. Patzoldt, W.L.; Tranel, P.J.; Hager, A.G. Variable herbicide responses among Illinois waterhemp (Amaranthus rudis and A. tuberculatus) populations. Crop Prot. 2002, 21, 707-712. [CrossRef]

30. Busi, R.; Dayan, F.E.; Francis, I.; Goggin, D.; Lerchl, J.; Porri, A.; Powles, S.B.; Sun, C.; Beckie, H.J. Cinmethylin controls multiple herbicide-resistant Lolium rigidum and its wheat selectivity is P450-based. Pest Manag. Sci. 2020, 76, 2601-2608. [CrossRef]

31. Andreasen, C.; Høgh, K.L.; Jensen, S.M. The Effect of Foliar and Soil Application of Flufenacet and Prosulfocarb on Italian Ryegrass (Lolium multiflorum L.) Control. Agriculture 2020, 10, 552. [CrossRef]

32. Cobb, A.; Reade, J.P.H. Herbicides and Plant Physiology, 2nd ed.; Wiley-Blackwell: Hoboken, NJ, USA, $2011 ;$ ISBN 9781444322491.

33. Rosenhauer, M.; Petersen, J. Bioassay Development for the Identification of Pre-emergence Herbicide Resistance in Alopecurus myosuroides (Huds.) Populations. Gesunde Pflanz. 2015, 67, 141-150. [CrossRef]

34. Cranmer, J.R.; Linscott, D.L. Effects of Droplet Composition on Glyphosate Absorption and Translocation in Velvetleaf (Abutilon theophrasti). Weed Sci. 1991, 39, 251-254. [CrossRef]

35. Varanasi, A.; Prasad, P.V.; Jugulam, M. Chapter Three-Impact of Climate Change Factors on Weeds and Herbicide Efficacy. In Advances in Agronomy; Sparks, D.L., Ed.; Academic Press: Cambridge, MA, USA, 2016; pp. 107-146. ISBN $0065-2113$.

36. Eppo. PP. 1/213 (4) Resistance risk analysis. Bull. OEPP/EPPO 2015, 45, 371-387. [CrossRef]

37. Heap, I.M. Identification and documentation of herbicide resistance. Phytoprotection 1994, 75, 85-90. [CrossRef] 